\title{
Arreglos conyugales en Baja California y sus jóvenes adultos
}

\section{Conyugal arrangements in Baja California and its young adults}

Norma Ojeda*

Resumen

La formación de uniones libres o consensuales ha ido en aumento en México y su región norte no es una excepción. Información del Censo Mexicano de Población y Vivienda de 2010 y de la Encuesta Sobre la Salud Reproductiva de los Adolescentes en Baja California, 2006, indica que la elección de la unión libre como arreglo conyugal se refleja de manera clara entre los y las jóvenes bajacalifornianas adultas en general, pero particularmente entre aquellos y aquellas que residen en Tijuana y Rosarito. Asimismo, la formación de uniones libres entre los y las jóvenes del estado parece estar asociada al papel que tradicionalmente ha tenido la unión libre en el proceso de formación familiar, mediante el nacimiento de hijos. Esto parece indicar una continuidad en la importancia que han tenido las uniones libres o consensuales en el proceso de formación familiar en México, pero ahora en proporciones mayores entre las y los jóvenes de las nuevas generaciones.

Palabras clave: unión libre, unión consensual, familia, jóvenes, nupcialidad.

\begin{abstract}
Uniones libres or consensual union formation has increased in Mexico and this is not an exception in its Northern region. Information from the Mexican Population and Household Census of 2010 and the Survey on Reproductive Health of Adolescents in Baja California, 2006 show that unión libre as an preferential type of conjugal arrangement is more clearly manifested among the Baja California's youth of both sexes in general and particularly among those residing in Tijuana and Rosarito. Also, union libre formation among the Baja California's youth is extensively associated with childbearing what seems to indicate continuity in its traditional role in the Mexican family formation process, but this is happening in higher proportions among the young adults of the new generations.

Keywords: conjugal arrangements, family, cohabitation, Mexican youth.
\end{abstract}

Recibido el 8 de noviembre de 2013.

Aprobado el 26 de mayo de 2014.

* Profesora de la San Diego State University e investigadora asociada de El Colegio de la Frontera Norte. Correo electrónico: ojedatec@aol.com 


\section{Introducción}

Éste es un estudio descriptivo de los arreglos conyugales establecidos entre la población residente en el estado norteño de Baja California. La información utilizada proviene del Censo de Población y Vivienda de 2010 y de la Encuesta Sobre la Salud Reproductiva de los Adolescentes en Baja California realizada en el año 2006 por El Colegio de la Frontera Norte. El principal objetivo es examinar la estructura por estado civil de la población y de sus arreglos conyugales, con especial atención en los jóvenes adultos y su creciente preferencia por la unión libre o consensual. Se examinan algunas variaciones que al respecto se presentan entre los distintos municipios del estado. Asimismo, se intenta hacer una primera aproximación analítica acerca del fenómeno de la formación de uniones libres entre la población joven adulta vinculado al proceso de formar una familia de procreación, mediante el nacimiento de hijos, a diferencia de ser un medio para establecer una relación de pareja sin hijos. Se adopta la definición de jóvenes adultos establecida en la Encuesta de Salud Reproductiva de los Adolescentes de Baja California, 2006, como aquellos hombres y mujeres que al momento de la encuesta tenían entre 18 y 29 años de edad. Se considera que este rango de edad permite examinar las uniones conyugales establecidas por personas que, al ser oficialmente reconocidas como adultos por el Estado mexicano, tienen autonomía legal para decidir formar una pareja conyugal mediante el matrimonio o bien una unión consensual, así como respecto de procrear hijos o no.

\section{Antecedentes}

La formación de las familias mexicanas es diversa por estar basada en distintos tipos de arreglos conyugales, según su condición de legalidad y sacralización; a saber, por medio de una unión libre o consensual, del matrimonio sólo religioso, del matrimonio sólo civil, o bien del matrimonio civil y religioso. La elección de alguno de estos distintos tipos de unión va a depender de las preferencias culturales de las personas y de sus particulares circunstancias sociales y posibilidades económicas para solventar los gastos asociados a la realización de cada uno de ellos (Ojeda, 2010). No 
obstante, el patrón conyugal dominante ha consistido en la preferencia cultural por el matrimonio civil y religioso como el más valorado, seguido por el matrimonio sólo civil y después por los otros dos tipos de unión (Díaz, 2002). Respecto de estos dos últimos, se tiene la circunstancia de que hasta la década de 1970, la tendencia fue de que tanto las uniones libres como los matrimonios sólo religiosos disminuyeran y los matrimonios sólo civiles aumentaran como resultado de la modernización del país y su creciente secularización; tendencia que en la década de 1980 cambió al aumentar las uniones libres, pero sin que ello modificara la primacía del matrimonio combinado civil y religioso entre los mexicanos.

Este orden jerárquico en la estructura de los arreglos conyugales persisitió hasta muy recientemente tanto a escala nacional como al interior de todas y cada una de las entidades federativas norteñas del país. Situación que, sin embargo, ha cambiado al observarse la presencia de interesantes modificaciones en dicho orden en la estructura conyugal a escala nacional y entre algunos estados de la región norte, pero no así en esta última al ser considerada como un todo. Entre los estados norteños que han experimentado importantes cambios en sus estructuras conyugales destaca el caso de Baja California, que se ha posicionado como líder al interior de la región en un proceso social tanto de des-institucionalización como de secularización acelerada de los arreglos conyugales (Ojeda, 2013a), lo que la hace ser un caso muy interesante de ser analizado.

El aumento generalizado de la unión libre o consensual en la región norte es un hecho observable entre todos los estados que la conforman, aunque esto se da con distintos grados de intensidad, incluyendo aquellos estados donde aún predomina el orden jerárquico tradicional en sus estructuras conyugales (Ojeda, 2013a). Esta situación sugiere la necesidad de considerar que no sólo es crecimiento de las uniones libres, sino también los posibles cambios que pudieran estarse generando acerca de la naturaleza social de dicho tipo de uniones. En este sentido, un aspecto central por ser analizado es la posible continuidad de las uniones libres como etapa inicial en el proceso de formación familiar versus la unión libre como medio para establecer relaciones de pareja pero sin la intensión expresa de procrear hijos y formar una familia.

Los arreglos conyugales de tipo consensual tienen una larga historia en varios países latinoamericanos y del Caribe (Rodríguez, 2004), donde, 
al igual que en México, forman parte de la fase inicial del proceso de formación de un número importante de familias de procreación que se mantienen como tal hasta la disolución conyugal de la pareja, o bien que se legalizan y/o sacralizan posteriormente mediante el matrimonio civil y/o religioso. Ésta ha sido una práctica de larga data y ampliamente extendida en México (Quilodrán, 2001; Díaz, 2002), la cual, sin embargo, de manera reciente ha observado algunos cambios importantes. Por un lado, se ha podido observar una disminución en la proporción de uniones libres que son legalizadas después de haberse formado (Ojeda, 2007); por otro lado, durante la última década se presenta un fuerte aumento de las uniones libres a escala nacional (Pérez y Esteve, 2012). Esta situación sugiere la presencia de modificaciones no sólo de tipo cuantitativo sino también probablemente de tipo cualitativo respecto de la naturaleza social de las uniones libres entre las generaciones más jóvenes. Sobre este aspecto, en un estudio cualitativo (Ojeda, 2009) llevado a cabo entre un grupo de jóvenes residentes en la ciudad fronteriza de Tijuana, Baja California, pudieron detectarse vestigios de cambio en las percepciones de las y los adolescentes acerca de las ventajas comparativas percibidas entre el matrimonio y la unión libre respecto de los planes de vida futuros relacionados con las relaciones de pareja, la educación y el trabajo. En lo general, los adolescentes de ambos sexos se muestran incrédulos acerca de que el matrimonio ofrezca ventajas comparativas claras para las mujeres respecto de lo que les ofrece la unión libre, pero tampoco parecen estar convencidos de que esta última sea mejor que el matrimonio (Ojeda, 2009).

Otro aspecto es la aparente continuidad en el comportamiento reproductivo similar de las mujeres casadas y las que viven en unión libre entre las generaciones más jóvenes al igual de lo que ocurría en generaciones anteriores. Ambos grupos de mujeres dan inicio a la formación de sus familias de procreación independientemente del tipo de arreglo conyugal en que se encuentran. Al respecto, en un estudio publicado en los inicios del presente milenio, Gómez (2001, p. 237) planteaba que, a escala nacional, ambos grupos de mujeres jóvenes procrean hijos pero lo hacen con interesantes diferencias entre sí según su nivel educativo. Dichas diferencias se refieren a la secuencia según como vivan los eventos de entrar en unión o matrimonio y el nacimiento del primer hijo; así como a la edad a 
la que experimentan tales eventos. ${ }^{1}$ La orientación pro familia de ambos tipos de arreglos conyugales es un tema importante de seguir siendo analizado para entender de mejor manera la naturaleza social del aumento de las uniones libres en el país. Es con esta intensión que se desarrolla este estudio acerca del aumento de la unión libre entre los arreglos conyugales de la población joven adulta examinando el caso específico del estado de Baja California.

\section{Metodología y fuentes de información}

Éste es un estudio descriptivo del estado actual de la estructura conyugal de la población de jóvenes adultos que radican en el estado de Baja California. Se hace especial énfasis en la importancia de las uniones libres o consensuales. Los jóvenes adultos son aquellos hombres y mujeres que tienen entre 18 y 29 años de edad. Se adoptó este concepto en función de las características de una de las principales fuentes de información utilizadas en el estudio. El análisis se basa en la información que al respecto proporcionan de manera complementaria el Censo Nacional de Población y Vivienda de México 2010 y la Encuesta de Salud Reproductiva de los Adolescentes de Baja California 2006. Esta última es una encuesta probabilística de hogares con representatividad municipal y estatal cuya población objetivo fueron los varones y las mujeres de edades entre 18 y 29 años residentes en el estado al momento de levantarse la encuesta (Palma y Reding, 2011, p. 84). El tamaño de la muestra es de 2395 mujeres y 1000 varones de estas edades.

${ }^{1}$ Entre las casadas, el nacimiento del primer hijo ocurre estando en matrimonio. Entre las unidas hay dos grupos. El primer grupo está formado principalmente por mujeres de baja o mediana escolaridad que establecen una unión libre como alternativa al matrimonio y tener un primer hijo confirma tal elección; mientras que el segundo grupo lo forman mujeres con mayor escolaridad quienes establecen una unión libre que se legaliza a consecuencia del primer embarazo cuando son menores de los 20 años de edad. 


\section{Acerca de los jóvenes en Baja California}

Baja California, al igual que otros estados fronterizos del norte de México, se caracteriza por su éxito económico basado en gran parte en el desarrollo de la industria maquiladora, por un lado, y sus muy altas tasas de crecimiento demográfico producto principalmente de altos niveles de inmigración, por el otro. Otra característica es la alta concentración espacial de su población, al tener, en el año 2010, casi la mitad (49.4\%) de sus 3155000 habitantes viviendo en uno solo (Tijuana) de sus cuatro municipios (Conapo, 2011, p. 13). Asimismo, la población del estado, y particularmente de Tijuana, tiene altas proporciones de personas en edades productivas y reproductivas debido a la fuerte atracción de migrantes de dichas edades, pero principalmente en los rangos de edad considerados como propios de la población joven (15 a 29 años) que, junto con el crecimiento demográfico natural, ha engrosado el volumen de este importante segmento de la población. Por ejemplo, para el año 2000, González (2011, p. 27) señala que mientras en $66 \%$ de las unidades domésticas del país residía algún joven, en Baja California la proporción era ligeramente superior con $66.8 \%$ y en Tijuana alcanzaba a ser de $68.4 \%$. Por otra parte, los índices de masculinidad de Baja California, y principalmente de Tijuana, son de los más altos del país (Ojeda, 2013a) por tenerse un número ligeramente mayor de varones por cada cien mujeres respecto de lo que se observa a escala nacional. Esto último se debe, en gran parte, a la selectividad por sexo de los migrantes que aún persiste en los distintos flujos migratorios, pero en especial entre los flujos internacionales en su paso hacia el país vecino del norte y de retorno de ese mismo país.

La condición migratoria de las personas es un rasgo importante de diferenciación social de la población en el estado por existir marcadas disparidades entre los inmigrantes y la población nativa, y en especial entre los jóvenes. Al respecto, González (2011) señala que existen menores niveles de escolaridad, tasas más altas de empleo y niveles de ingreso menores en los hogares de los jóvenes inmigrantes en comparación con los jóvenes nativos de Baja California. En otro estudio, Coubès y González (2011) indican que hay proporciones más altas de jóvenes en ocupaciones que requieren de mayor escolaridad y con mejores salarios entre los nativos de Baja California que entre los jóvenes inmigrantes. Por su parte, Yolanda 
Palma (2011) se refiere al comportamiento sexual y reproductivo de las jóvenes de 20 a 29 años que radican en Tijuana. La autora encuentra que estas jóvenes son más precoces que sus contrapartes a escala nacional, pero aclara que las jóvenes tijuanenses que nacieron fuera de Baja California son especialmente más precoces que las nacidas en el estado. Esta situación dificulta el análisis del comportamiento sexual y reproductivo de la población joven del estado debido, entre otras razones, a la heterogeneidad cultural de Baja California y en especial de Tijuana, dados los múltiples orígenes de su población migrante, proveniente de todas las regiones del país. Finalmente, respecto de la formación de uniones libres, Norma Ojeda (2013a) encuentra que la probabilidad de establecer una unión consensual en lugar de casarse entre las jóvenes tijuanenses es mayor entre las inmigrantes provenientes de los estados del sur del país que entre las inmigrantes de otros estados y que las nacidas en Baja California. El conjunto de estos aspectos seguramente influye en la vida cotidiana de la población joven del estado. En el interés por contribuir de alguna manera a comprender de mejor manera el comportamiento demográfico de Baja California, a continuación se presentan los hallazgos obtenidos en el estudio sobre la estructura de los arreglos conyugales de la población de jóvenes adultos del estado.

\section{Resultados}

\section{Estado civil y arreglos conyugales} de la población en la región norte de México

La distribución de la población según su estado civil es un aspecto básico del comportamiento relacionado con la nupcialidad en una sociedad. Al respecto, importa diferenciar entre la población alguna vez unida conyugalmente y la población nunca unida o soltera; los distintos tipos de arreglos conyugales de las personas que, al momento del conteo censal, estaban casadas o unidas; así como los tipos de disolución conyugal experimentada por la población alguna vez unida pero que, al momento del censo, ya no lo estaba. Este tipo de información nos permite no solamente identificar el número de efectivos en cada una de estas categorías de 
estado civil, sino también nos da una idea acerca de los patrones sociales subyacentes en la estructura conyugal y familiar de dicha sociedad. Es con esta intensión que a continuación se presentan algunos datos sobre la población mexicana residente en la región norte del país y en particular en el estado norteño de Baja California.

La información censal del año 2010, que se presenta en el cuadro 1, nos permite ver que la población de 12 y más años de edad residente en la región norte de México presenta una distribución por estado civil prácticamente igual que la del país en su conjunto. Si bien la región norte tiene un poco menos de población soltera que el país en su conjunto $(33.5 \%$ y $35.2 \%$, respectivamente), ambas unidades geográficas tienen la misma proporción de población unida o casada, con alrededor del $55 \%$ de casos cada una. Asimismo, el total nacional y su región norte tienen las mismas proporciones de separados y viudos y se diferencian por sólo un medio punto porcentual más en la categoría de divorciados en la región norte.

Estos resultados nos podrían hacer pensar que las poblaciones residentes en los estados del norte se comportan de igual modo que el total de la población mexicana. La comparación de las distribuciones por estado civil

\section{Cuadro 1. Estado civil de la población de 12 y más años de edad en distintos estados del norte de México, 2010 (\%)}

\begin{tabular}{|c|c|c|c|c|c|c|c|c|c|}
\hline \multirow[b]{2}{*}{ Lugar } & \multirow[b]{2}{*}{ Total } & \multirow[b]{2}{*}{ Soltera } & \multicolumn{3}{|c|}{ Matrimonio } & \multirow[b]{2}{*}{$\begin{array}{l}\text { Unión } \\
\text { libre }\end{array}$} & \multirow[b]{2}{*}{ Separada } & \multirow[b]{2}{*}{ Divorciada } & \multirow[b]{2}{*}{ Viuda } \\
\hline & & & Civil & Religioso & $\begin{array}{c}\text { Civil y } \\
\text { Religioso }\end{array}$ & & & & \\
\hline México & 100 & 35.2 & 13.2 & 1.7 & 25.8 & 14.4 & 3.8 & 1.5 & 4.4 \\
\hline $\begin{array}{l}\text { Región } \\
\text { Norte }\end{array}$ & 100 & 33.5 & 17.2 & 0.7 & 24.3 & 14.2 & 3.8 & 2.2 & 4.4 \\
\hline $\begin{array}{c}\text { Baja } \\
\text { California } \\
\end{array}$ & 100 & 34.9 & 17.7 & 0.9 & 16.8 & 19.3 & 4.9 & 2.4 & 3.1 \\
\hline Sonora & 100 & 34.7 & 16.7 & 0.1 & 21 & 16.4 & 4.3 & 2.1 & 4.7 \\
\hline Chihuahua & 100 & 33.5 & 15.3 & 0.9 & 22.8 & 17.3 & 3.4 & 2.5 & 4.2 \\
\hline Tamaulipas & 100 & 33.2 & 19.6 & 1 & 21.4 & 15.3 & 3.8 & 1.7 & 4 \\
\hline Coahuila & 100 & 32.8 & 18.7 & 0.4 & 27.8 & 10.5 & 3.3 & 2 & 4.9 \\
\hline Nuevo León & 100 & 33.4 & 16.5 & 0.3 & 31.8 & 9.1 & 3.3 & 1.8 & 4.1 \\
\hline
\end{tabular}

Fuente: Estimaciones propias. Censo Nacional de Población y Vivienda, México, 2010. 
entre las varias entidades federativas que conforman a la región norte, sin embargo, nos indica la necesidad de ser prudentes en este sentido dado que existen algunas diferencias importantes entre ellas que pudieran estar sugiriendo dinámicas sociales un tanto diferentes en el comportamiento de sus distintas poblaciones y sus arreglos conyugales. Nótese, por ejemplo, en el cuadro 1, que en Baja California y Sonora la proporción de solteros es ligeramente mayor que en el resto de los estados de la región. Por su parte, las proporciones de la población casada o unida entre estados oscilan entre $54.1 \%$ y $57.4 \%$, con Sonora y Nuevo León situados en los respectivos casos extremos. Y las poblaciones de viudos están en el rango de $4.0 \%$ al $4.9 \%$ entre los distintos estados, con la excepción del Baja California donde esta categoría aglutina únicamente a $3.1 \%$ del total de la población de 12 y más años de edad.

También se observan algunas interesantes diferencias en las proporciones de divorciados y separados entre los estados norteños. Si bien en todos los casos se observan cifras que indican más personas separadas que divorciadas, siguiendo el tradicional patrón nacional (Ojeda, 2010) tenemos la situación de que, al considerar de manera conjunta a los divorciados y separados, el estado de Nuevo León presenta el porcentaje más bajo de personas con uniones conyugales disueltas de manera voluntaria con sólo $5.1 \%$ de casos, seguido de Coahuila y Tamaulipas con valores de $5.3 \%$ y $5.5 \%$ respectivamente. Por su parte, Chihuahua y Sonora presentan valores alrededor de 6\%, con Sonora a la cabeza; en tanto que Baja California se dispara con el valor más alto de población divorciada y separada con $7.3 \%$ de casos.

Los datos arriba descritos indican una cierta heterogeneidad en el comportamiento por estado civil de la población del norte de México y nos invitan a considerar otros aspectos relacionados, como es el caso de las estructuras conyugales de la población norteña. Sobre este particular, el cuadro 2 presenta la distribución porcentual de los distintos arreglos conyugales, según el censo de 2010, para la región norte, las distintas entidades federativas que la conforman y para el país en su conjunto. En el nivel nacional, observamos que el matrimonio civil y religioso sigue siendo el tipo de arreglo conyugal más frecuente con $46.7 \%$ del total de las uniones conyugales del país; le sigue la unión libre que ya ocupa el segundo lugar con una frecuencia de $26.2 \%$, seguida muy de cerca por el matrimonio 
Cuadro 2. Estructura conyugal de la población en distintos estados del norte de México, 2010 (\%)

\begin{tabular}{|c|c|c|c|c|c|}
\hline \multirow{2}{*}{ Lugar } & \multirow{2}{*}{ Total } & \multicolumn{3}{|c|}{ Matrimonio } & \multirow{2}{*}{$\begin{array}{c}\text { En unión } \\
\text { libre }\end{array}$} \\
\hline & & Civil & Religioso & Civil y Religioso & \\
\hline México & 100 & 23.9 & 3.2 & 46.7 & 26.2 \\
\hline Región Norte & 100 & 30.8 & 0.8 & 43 & 25.4 \\
\hline Baja California & 100 & 32.6 & 0.9 & 30.9 & 35.6 \\
\hline Sonora & 100 & 30.6 & 0.9 & 38.5 & 30 \\
\hline Chihuahua & 100 & 27.3 & 1.2 & 40.7 & 30.8 \\
\hline Tamaulipas & 100 & 34.5 & 1 & 37.6 & 26.9 \\
\hline Coahuila & 100 & 32.6 & 0.8 & 48.3 & 18.3 \\
\hline Nuevo León & 100 & 28.6 & 0.5 & 55.2 & 15.7 \\
\hline
\end{tabular}

Fuente: Estimaciones propias. Censo Nacional de Población y Vivienda, México, 2010.

sólo civil al que le corresponde el tercer lugar por representar $24.0 \%$ del total de los casos; en tanto que el matrimonio sólo religioso apenas alcanza $3.1 \%$ del total de los arreglos conyugales en el país. Esta estructura de los arreglos conyugales a escala nacional representa un importante cambio en la nupcialidad mexicana por alejarse del patrón tradicional.

Al examinar el caso norteño, sin embargo, encontramos que dicho cambio no se presenta de igual manera en la región donde, como podemos ver en propio cuadro 2, el orden jerárquico entre los distintos arreglos conyugales varía entre los estados. A nivel de la región, el matrimonio civil-religioso y el matrimonio sólo civil siguen ocupando el primero y segundo lugares, respectivamente, sugiriendo una continuidad en el patrón tradicional de la estructura conyugal mexicana con una tendencia ascendente del matrimonio sólo civil en todos los estados de la región norte. En cambio, el análisis de la estructura conyugal al interior de la región nos permite ver interesantes variaciones entre los estados que la componen y que apuntan hacia una importancia creciente de la unión libre y un correspondiente descenso del matrimonio.

En el momento censal de 2010, la estructura conyugal de la población residente en la región norte estaba compuesta en $43 \%$ por matrimonios 
civil-religiosos, casi $31 \%$ por matrimonios sólo civiles, una cuarta parte (25.4\%) por uniones libres y por una insignificante proporción de matrimonios sólo religiosos $(0.81 \%)$. Cuatro de los cinco estados norteños presentan este mismo patrón, destacando Nuevo León por tener el porcentaje más alto de matrimonios y el más bajo de uniones libres: 55.2\% de las personas estaba casado en matrimonio civil y religioso, $28.6 \%$ casados sólo por el civil y $15.7 \%$ en unión libre. Le siguen en esta misma dirección, Coahuila y Tamaulipas con proporciones similares. Mientras que en Chihuahua y Sonora, si bien el matrimonio sólo civil y religioso es también el más numeroso, seguido del matrimonio sólo civil, se tiene la circunstancia de que la proporción de uniones libres llega a concentrar $30.8 \%$ y $30.0 \%$, respectivamente, de la población unida. Por su parte, Baja California, en el extremo opuesto, se caracteriza por tener una distribución porcentual casi equilibrada entre los dos tipos de matrimonios y la unión libre. En este estado las uniones libres ya son el tipo de unión más numeroso al concentrar $35.6 \%$ del total de las personas unidas conyugalmente; en tanto que el matrimonio sólo civil aglutina $32.6 \%$ y el matrimonio civil y religioso casi $31 \%$.

La importancia creciente de la unión libre en la región norte se manifiesta en el hecho de representar, con excepción de Coahuila y Nuevo León, entre aproximadamente 27\% y $36 \%$ del total de los arreglos conyugales, destacando el estado de Baja California donde la unión libre representa el tipo de unión más frecuente tanto al interior del estado como en la región, por ser un tercio del total de los arreglos conyugales. En un estudio reciente (Ojeda, 2013a) sobre el mismo tema, pudo observarse que el aumento de la unión libre es una realidad palpable en todos y cada uno de los estados del norte del país, incluso en aquellos donde este tipo de unión representa aún porcentajes relativamente bajos, como son los casos de Nuevo León y Coahuila. Información proveniente del mismo estudio se presenta en las figuras 1 y 2 donde podemos observar las proporciones de uniones libres para las poblaciones de hombres y mujeres, por separado, en los años censales de 2000 y 2010 para el total nacional, el conjunto de la región norte y cada una de las cinco entidades federativas norteñas. Al respecto, nótese cómo las proporciones de la región fronteriza en su conjunto son ligeramente menores que las del país en ambos momentos censales, tanto entre la población masculina como en la femenina; situación que se 
explica por el hecho de que los estados norteños se comportan de manera heterogénea al presentar proporciones tanto menores como superiores al nivel nacional en cada año.

Se confirma Baja California como el estado norteño que tiene las proporciones más altas de uniones libres, en tanto que Nuevo León tiene los índices más bajos en los dos años censales, sugiriendo un patrón regional en la frecuencia y la tendencia al aumento de las uniones libres que se dibuja de menos a más con una orientación que va del este al oeste de la franja fronteriza norteña. Asimismo, nótese que la proporción de uniones consensuales que Baja California tenía en el año 2000 era ya ligeramente superior al que 10 años después presenta el país en su conjunto y su región norteña, tanto entre hombres como en mujeres. Finalmente, véase que las proporciones son muy similares entre los hombres y las mujeres para cada año censal y que las proporciones aumentaron de manera uniforme

Figura 1. Proporción de uniones libres entre la población masculina de la región norte de México, 2000 y 2010

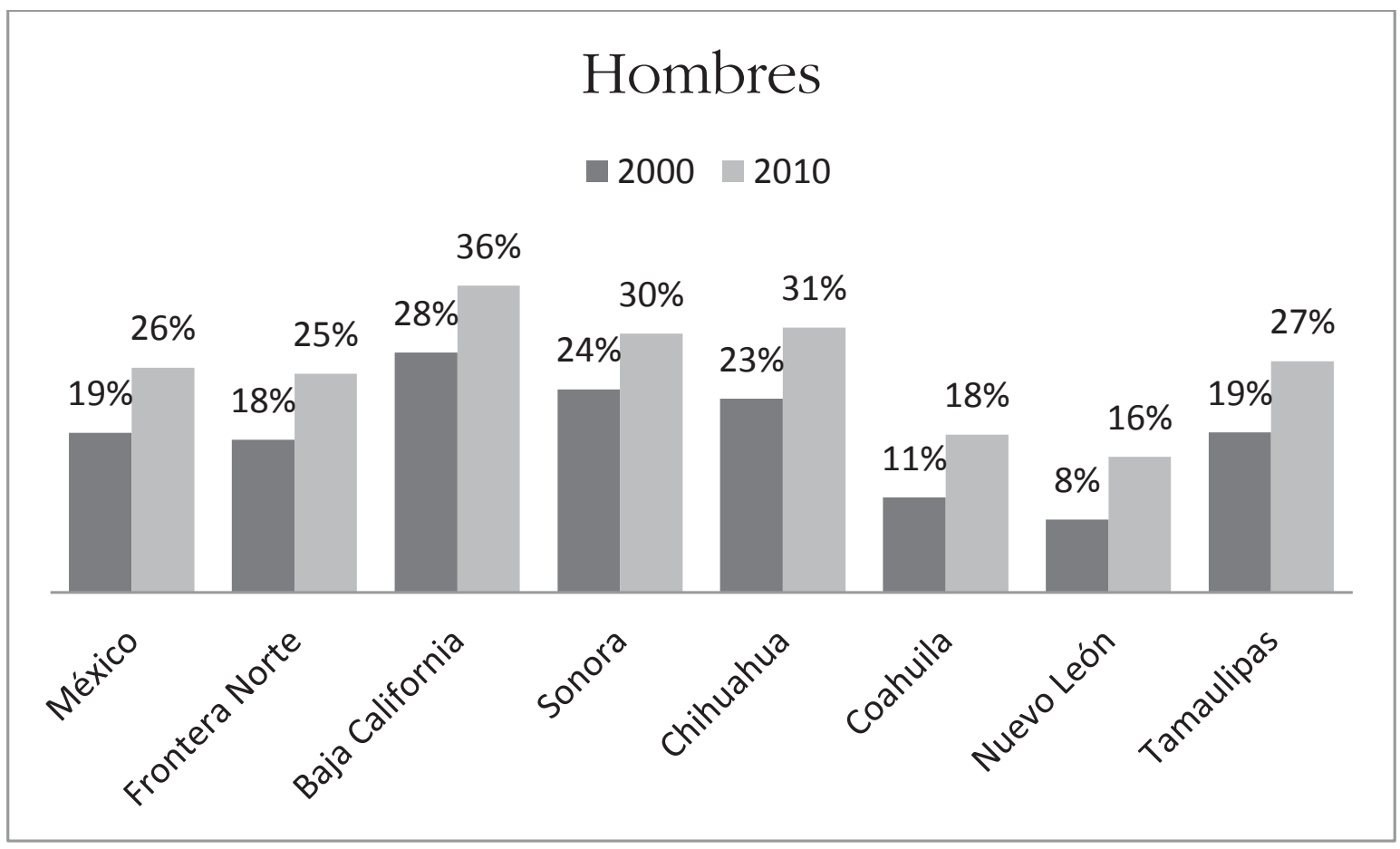

Fuente: Estimaciones propias. Censos nacionales de población y vivienda, México, 2000 y 2010. 
Figura 2. Proporción de uniones libres entre la población femenina en la región norte de México, 2000 y 2010

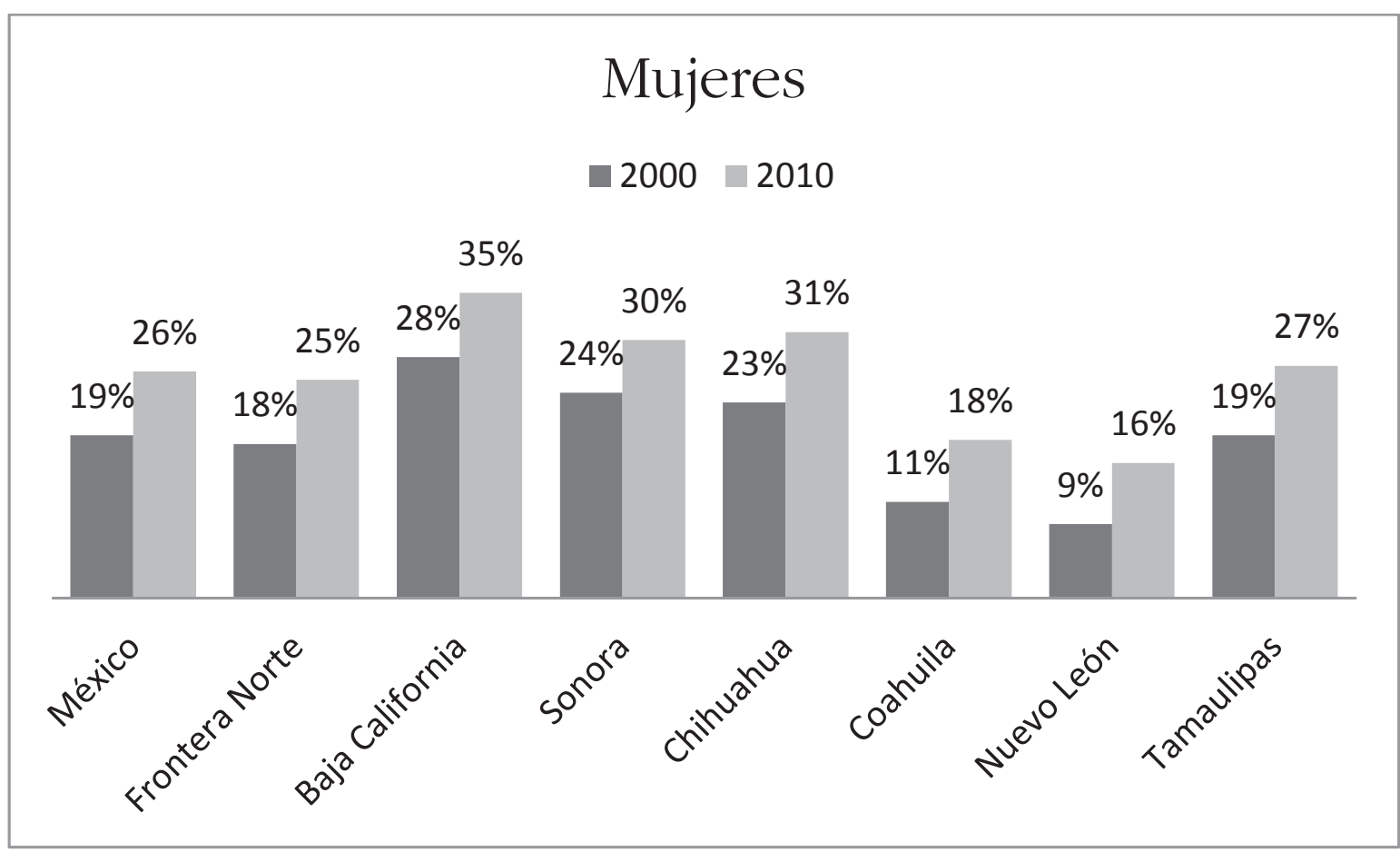

Fuente: Estimaciones propias. Censos nacionales de población y vivienda, México, 2000 y 2010.

entre las poblaciones de cada sexo en cada una de las unidades geográficas consideradas.

Explicar las diferencias entre los estados respecto de sus proporciones de uniones libres requiere considerar múltiples factores cuyo análisis rebasan los objetivos de este estudio. Sin embargo, un factor que nos es obligado considerar aquí es la estructura por sexo y edad de los estados. La información que al respecto nos proporciona el Censo de Población del año 2010 nos permite observar la presencia de interesantes diferencias en las estructuras por edad entre los estados (ver figuras 3-10), producto también de múltiples factores, entre los que destacan las migraciones. Estas diferencias, sin embargo, por sí solas no podrían explicar las variaciones en los porcentajes de uniones libres entre los estados, dado que el número de hombres y mujeres no indica notables desequilibrios entre los sexos que pudieran aludir al por qué unirse en lugar de casarse. Así, 
por ejemplo, al comparar los casos extremos de Baja California y Nuevo León que tienen, respectivamente, los porcentajes más altos y más bajos de uniones libres, notamos que este último presenta un mayor equilibrio numérico entre los sexos a todas las edades. En cambio Baja California presenta un ligero déficit de hombres de 20-34 años respecto de las mujeres de las mismas edades. Si bien es posible que dicho déficit impacte el número de hombres disponibles para casarse, lo mismo podemos pensar acerca de los hombres disponibles para unirse consensualmente. Además, es de tomar en cuenta que el impacto de dicho déficit se suaviza por la costumbre de que, en la mayoría de los casos, los hombres se siguen casando con mujeres de su misma edad o menores que ellos. Por lo cual sería necesario considerar también el peso de otros factores para explicar las diferencias que se presentan entre los distintos estados respecto de la proporción de uniones libres.

Figura 3

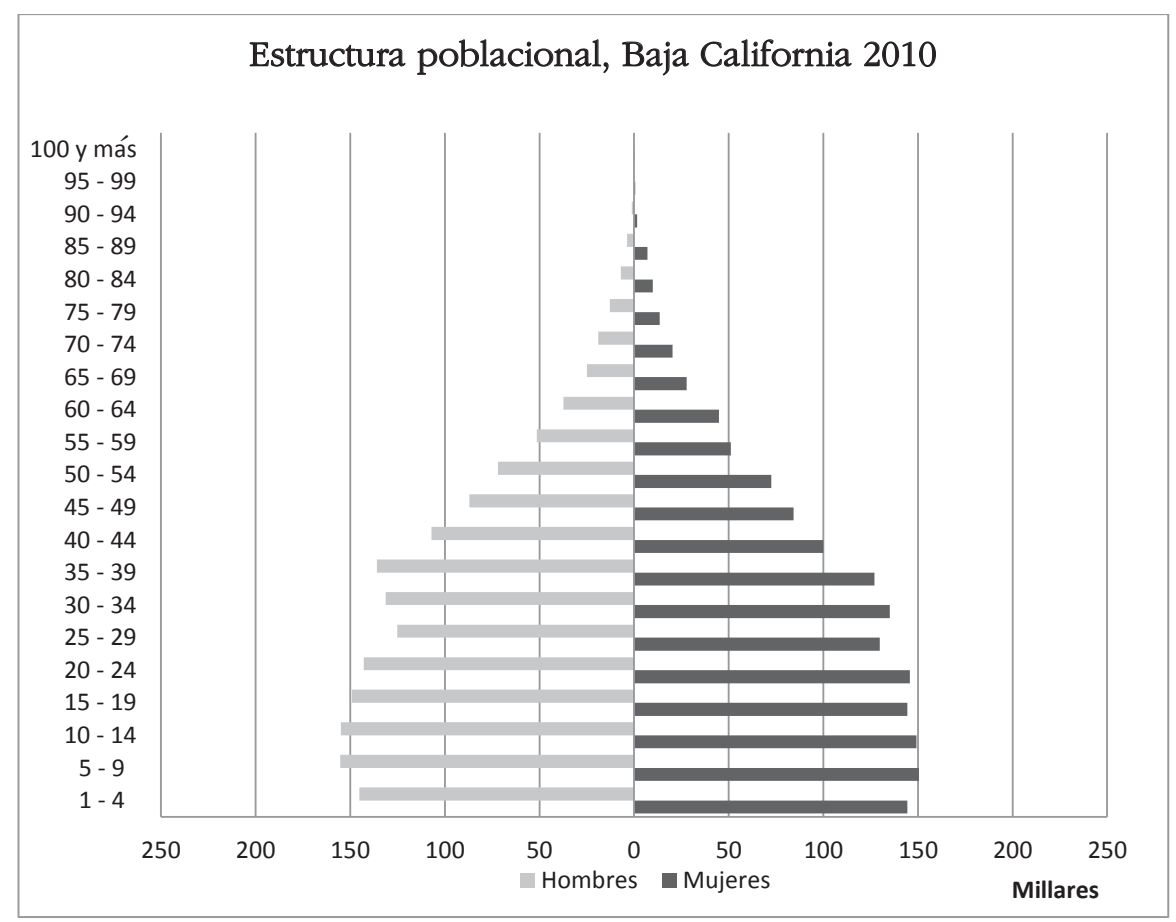

Fuente: Censo de Población y Vivienda 2010. 


\section{Figura 4}

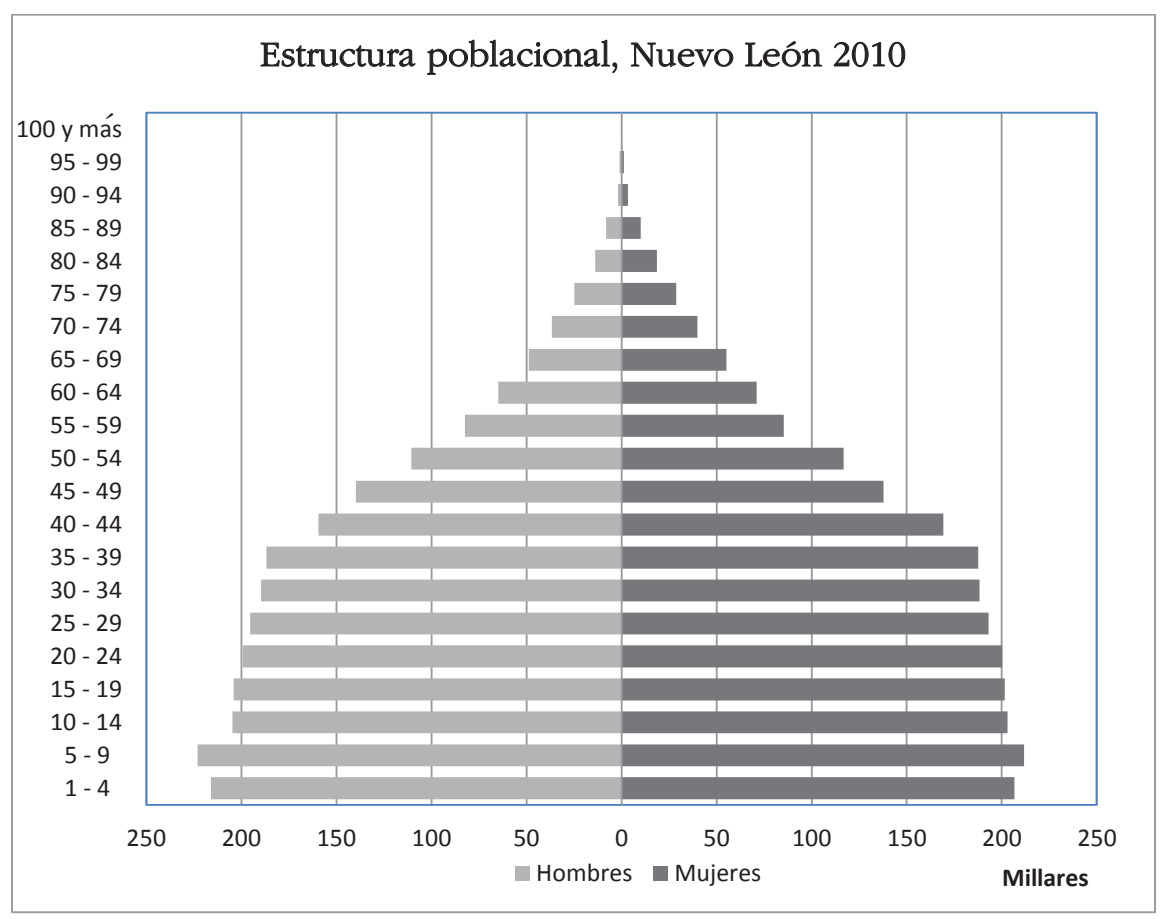

Fuente: Censo de Población y Vivienda 2010.

Figura 5

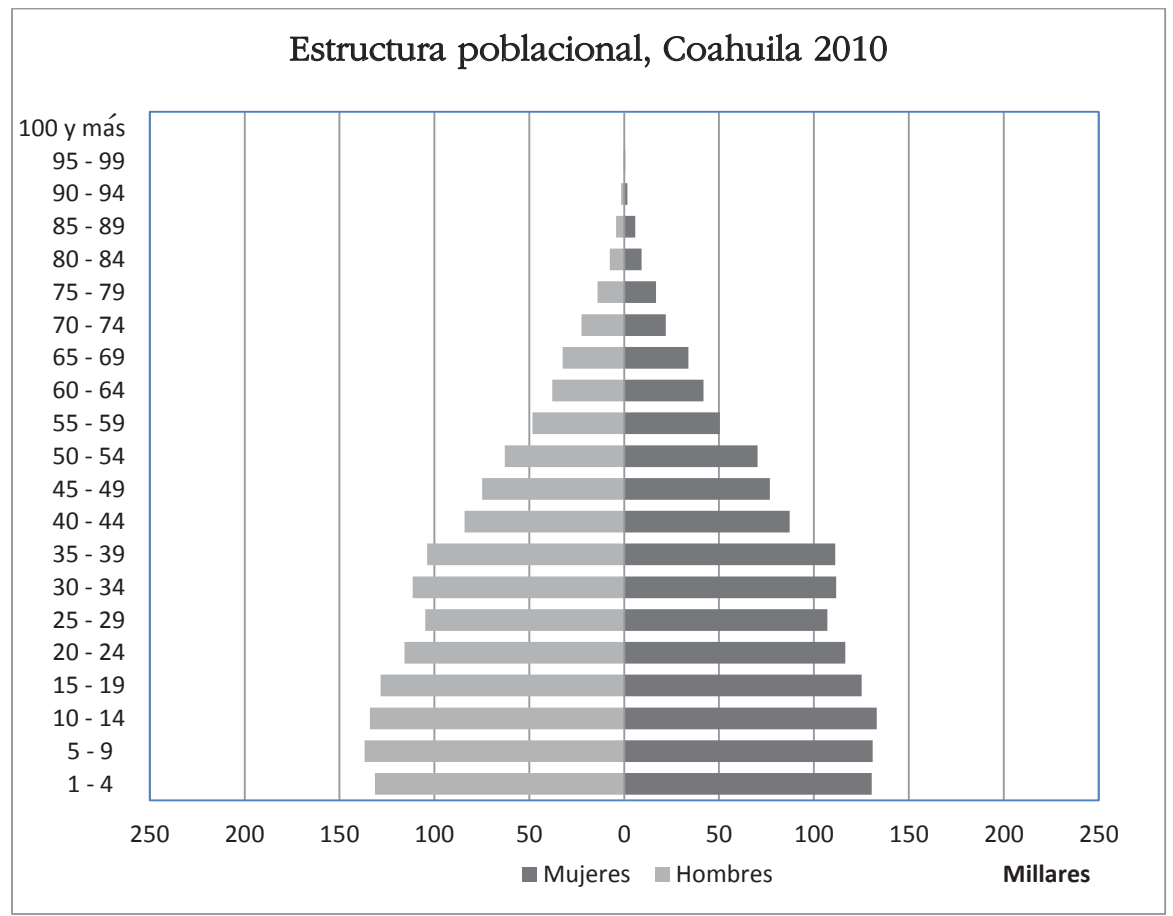

Fuente: Censo de Población y Vivienda 2010. 
Figura 6

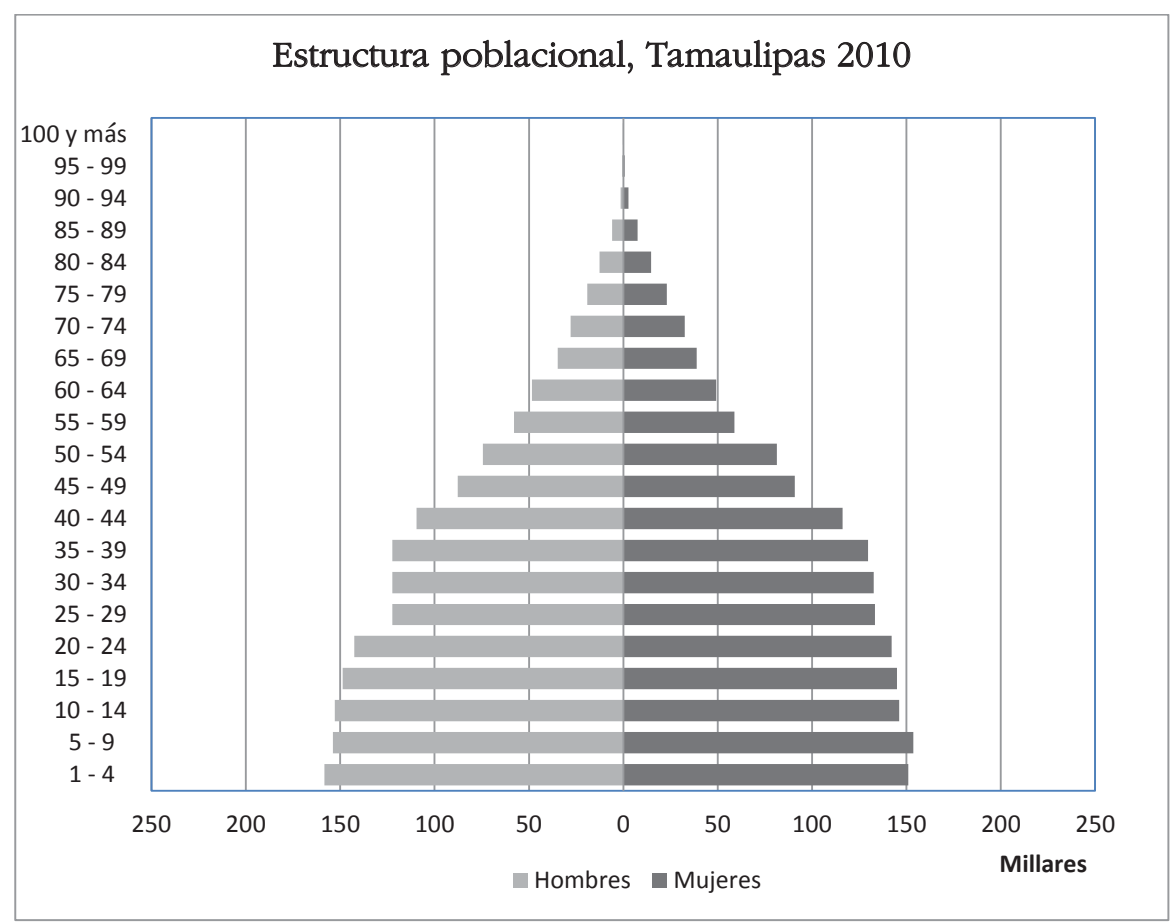

Fuente: Censo de Población y Vivienda 2010.

Figura 7

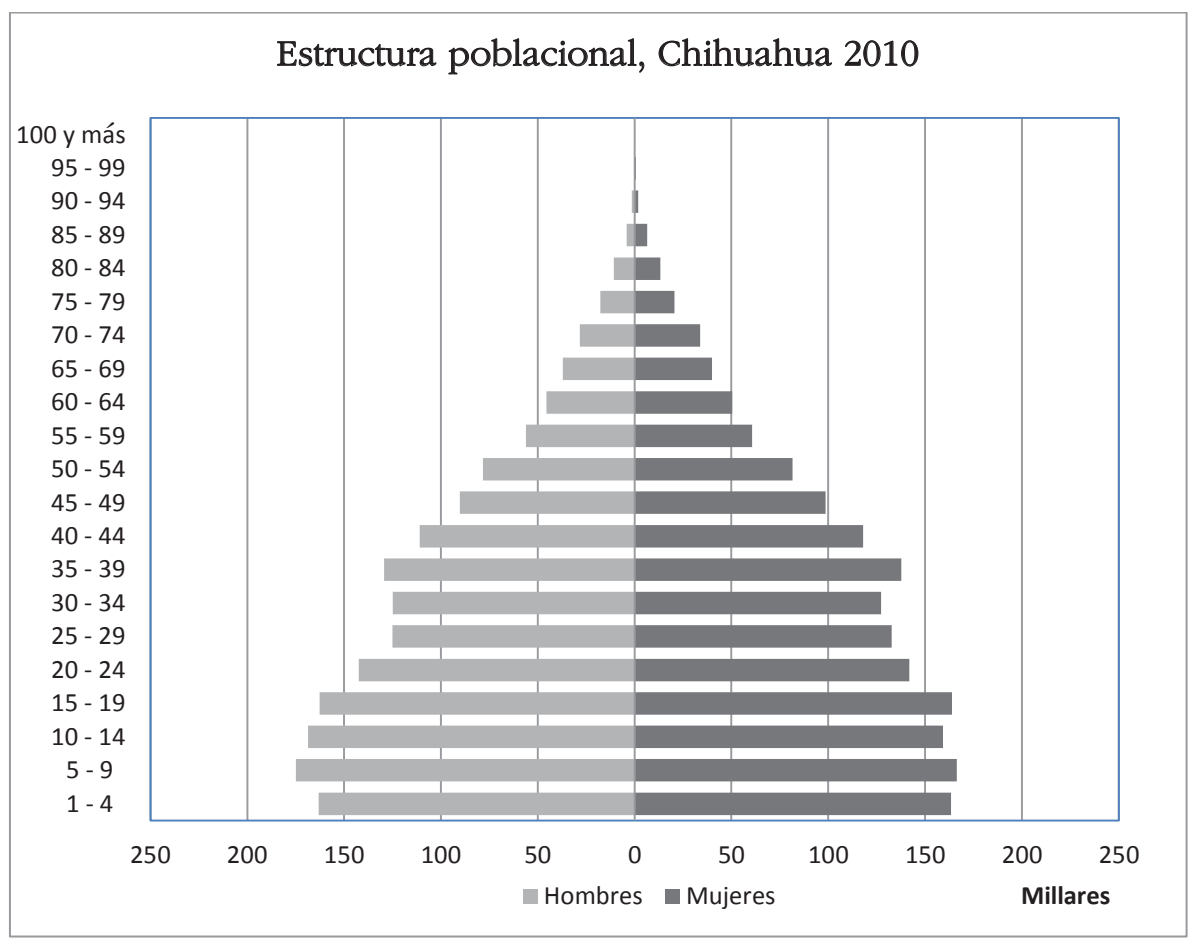

Fuente: Censo de Población y Vivienda 2010. 
Figura 8

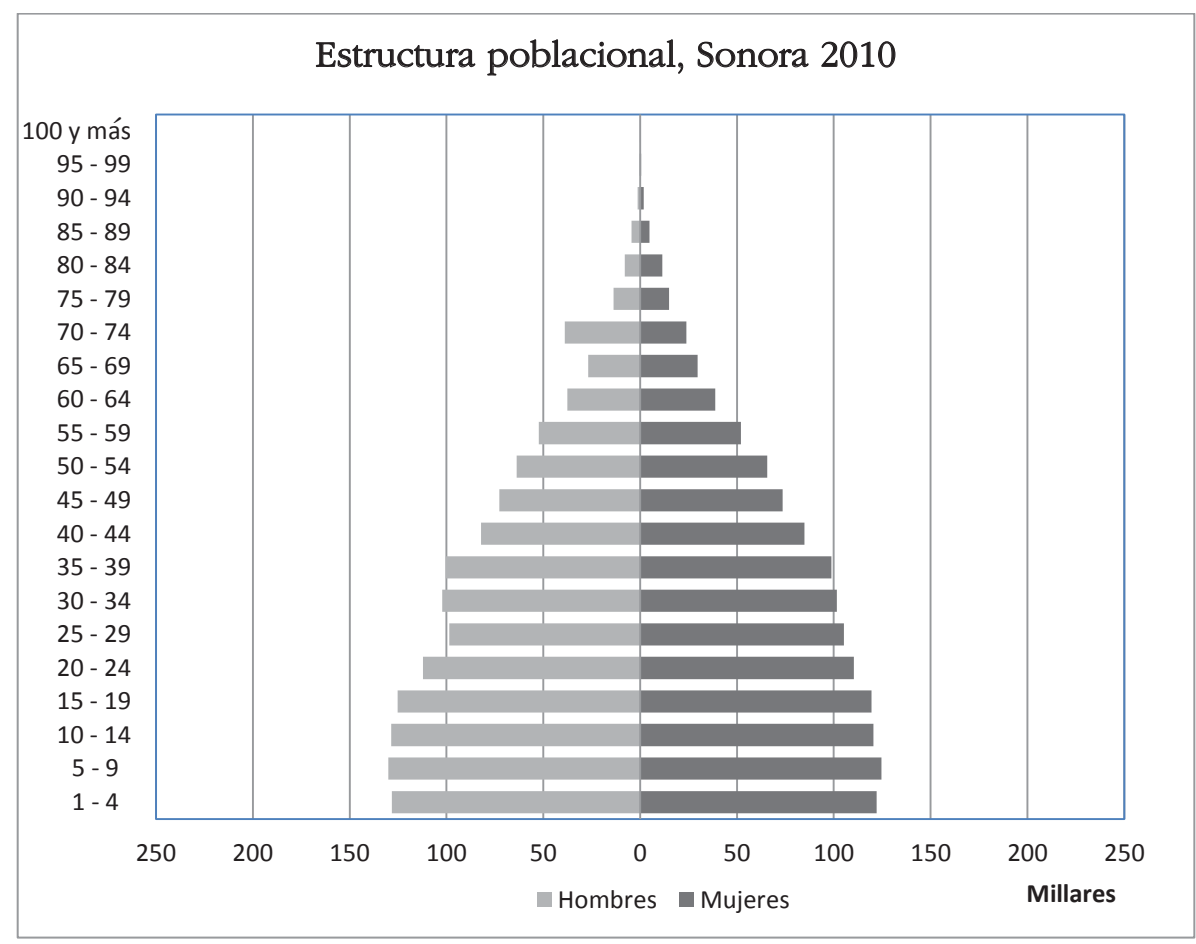

Fuente: Censo de Población y Vivienda 2010.

\section{Figura 9. Estructura poblacional}

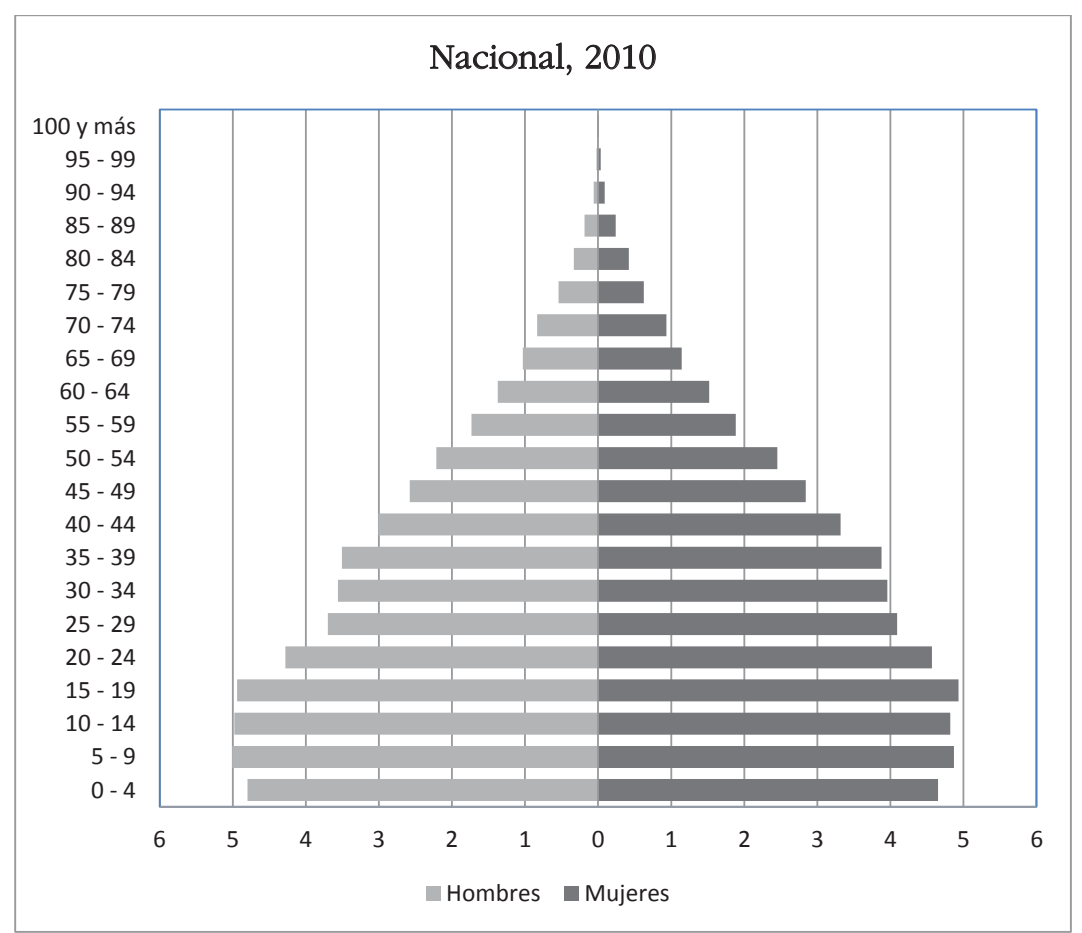

Fuente: Censo de Población y Vivienda 2010. 
Figura 10

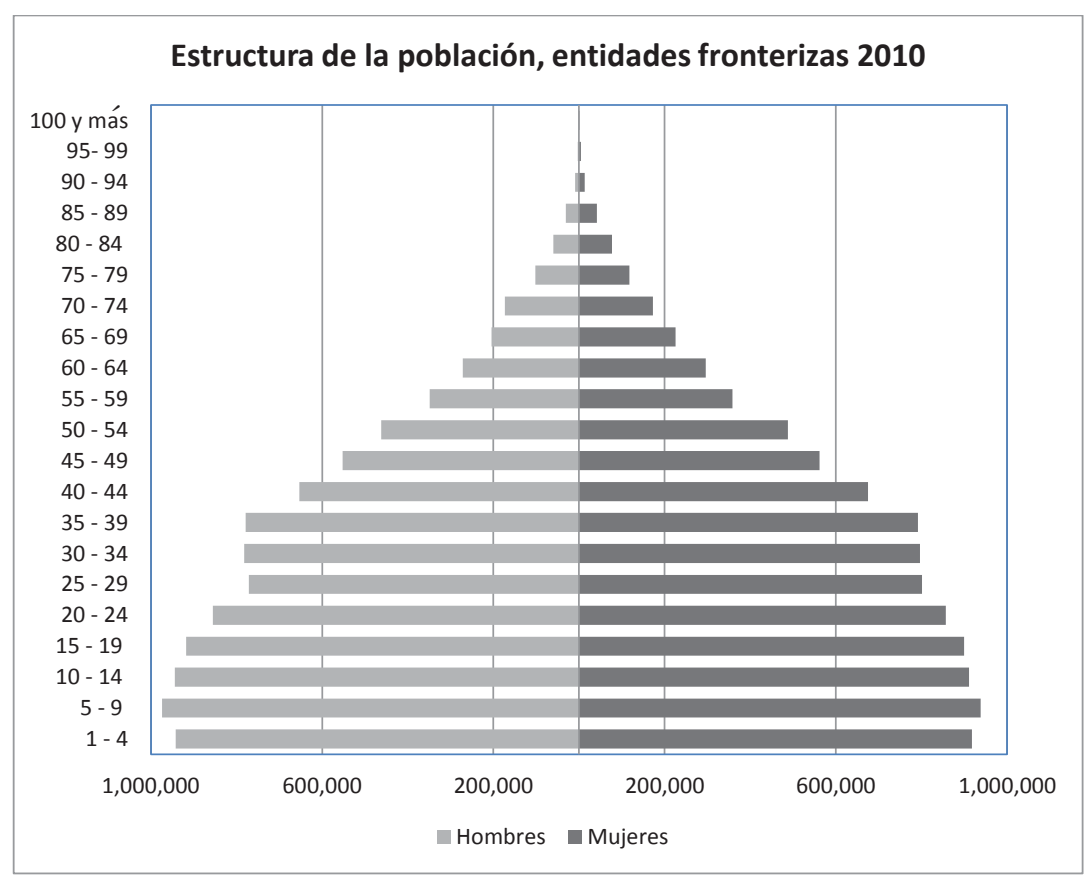

Fuente: Censo de Población y Vivienda 2010.

\section{Estado civil y estructura conyugal de la población en Baja California}

Con el propósito de profundizar en el caso de Baja California, a continuación se presenta la distribución de la población, según su estado civil, en los cinco municipios del estado. Se observará que la proporción de la población soltera es prácticamente la misma en todos los municipios por oscilar entre 32\% y 35\% del total de la población de 12 y más años de edad en cada uno de ellos. Asimismo, la población que al momento del conteo censal declaró estar casada o unida representa poco más de la mitad de la población total de estas edades en todos los municipios, al comprender entre $52 \%$ y $56 \%$, teniendo a Tecate y Rosarito a la cabeza con el porcentaje más alto de población casada o unida ( $56.0 \%$ en ambos), y en el extremo opuesto, a Mexicali con el porcentaje más bajo (52.0\%). Por su parte, la población divorciada y separada en los distintos municipios representa entre $7 \%$ y $8 \%$, y la de viudos entre $3 \%$ y $4 \%$. En conjunto, estas cifras indican 


\section{Cuadro 3. Estado civil de la población de 12 y más años de edad en distintos municipios de Baja California (\%)}

\begin{tabular}{|l|c|c|c|c|c|c|}
\hline \multicolumn{1}{|c|}{ Estado conyugal } & $\begin{array}{c}\text { Baja } \\
\text { California }\end{array}$ & Ensenada & Mexicali & Tecate & Tijuana & Rosarito \\
\hline Vive con su pareja en unión libre & 19 & 19 & 16 & 19 & 20 & 21 \\
\hline Está separado/a & 5 & 5 & 4 & 4 & 5 & 6 \\
\hline Está divorciado/a & 3 & 3 & 3 & 3 & 2 & 2 \\
\hline Es viudo/a & 4 & 4 & 4 & 3 & 3 & 3 \\
\hline Está casado/a)sólo por el civil & 17 & 16 & 17 & 16 & 17 & 16 \\
\hline Está casado/a sólo religiosamente & 1 & 1 & 1 & 1 & 1 & 1 \\
\hline Está casado/a civil y religiosamente & 17 & 17 & 19 & 20 & 16 & 18 \\
\hline Está soltero/a/ & 34 & 35 & 36 & 34 & 36 & 33 \\
\hline Total & 100 & 100 & 100 & 100 & 100 & 100 \\
\hline
\end{tabular}

Fuente: Estimaciones propias. Censo Nacional de Población y Vivienda, México, 2010.

una distribución por estado civil en Baja California muy uniforme, con sólo ligeras variaciones entre sus municipios.

En cambio, la estructura de los arreglos conyugales de los municipios está lejos de ser uniforme. Esto es considerando a todas las personas de 12 y más años de edad que, al momento censal de 2010, ya estaban casadas o unidas. Información proveniente de otro estudio anterior (Ojeda, 2013b) y que se presenta en el cuadro 4, nos permite ver interesantes diferencias entre las estructuras conyugales de los distintos municipios bajacalifornianos. Nótese cómo en tres de los cinco municipios poco más de una tercera parte del total de la población unida vive en unión libre, representando el tipo de arreglo conyugal más frecuente. Véase cómo sólo en Mexicali y Tecate el matrimonio civil y religioso continúa teniendo la primacía en sus respectivas estructuras conyugales; aunque esto ocurre no por mucho, especialmente en el caso de Tecate, donde sólo medio punto porcentual más favorece a los matrimonios respecto de las uniones libres (35.1\% vs. 34.6\%, respectivamente). Por su parte, Tijuana y Rosarito tienen las proporciones más altas de uniones libres con $37.4 \%$ y $37.1 \%$ de su población unida de manera consensual, respectivamente; seguidos muy de cerca por Ensenada con 36.3\% de sus casos en esta misma situación. Asimismo, nótese que 
Cuadro 4. Estructura conyugal de la población de 12 años y más en distintos municipios de Baja California, 2010 (\%)

\begin{tabular}{|c|c|c|c|c|c|}
\hline \multirow{2}{*}{\begin{tabular}{c} 
Municipio \\
\multirow{2}{*}{ Total }
\end{tabular}} & \multicolumn{4}{|c|}{ Matrimonio } & \multirow{2}{*}{$\begin{array}{c}\text { En unión } \\
\text { libre }\end{array}$} \\
\cline { 3 - 5 } & & Civil & Religioso & Civil y religioso & 35.6 \\
\hline Baja California & 100 & 32.6 & 0.9 & 30.9 & 36.3 \\
\hline Ensenada & 100 & 30 & 1.6 & 32.1 & 30.6 \\
\hline Mexicali & 100 & 32.7 & 0.9 & 35.8 & 34.6 \\
\hline Tecate & 100 & 29.4 & 0.9 & 35.1 & 37.5 \\
\hline Tijuana & 100 & 32.3 & 0.9 & 29.3 & 37.1 \\
\hline Rosarito & 100 & 28.3 & 1.8 & 32.8 & \\
\hline
\end{tabular}

Fuente: Estimaciones propias. Censo Nacional de Población y Vivienda, México, 2010.

en Tijuana incluso los matrimonios civiles son ya más numerosos que los matrimonios civil-religiosos, empujando a estos últimos a ocupar el tercer lugar en la estructura conyugal del municipio al igual de lo que ocurre a nivel del estado en su conjunto. Finalmente, llama la atención que el matrimonio sólo religioso prácticamente está en extinción, al situarse en porcentajes que van de $1 \%$ a $1.8 \%$ entre los cinco municipios.

La importante creciente de las uniones libres en Baja California, al igual de lo que ocurre en otras partes de México y particularmente en la región norte del país, pudiera deberse en parte a la preferencia por este tipo de arreglo conyugal entre los jóvenes que se unen por primera vez y que sería importante analizar. Pero desafortunadamente la información censal no nos permite examinar este aspecto debido a que en la declaración del estado civil no se especifica el orden de los matrimonios o uniones y, por lo mismo, no podemos diferenciar entre la primera unión o matrimonio y las ulteriores uniones o matrimonios de las personas. En cambio, algunas encuestas demográficas sí nos permiten hacer este tipo de análisis, como es el caso de la Encuesta de Salud Reproductiva de los Adolescentes en Baja California, realizada por El Colegio de la Frontera Norte en el año 2006 y que tiene cobertura a nivel estatal. Es con base en esta fuente de información que a continuación se analizan el estado civil y los arreglos conyugales de la población joven de Baja California. Importa señalar que 
se entiende por población joven a aquella que al momento de la encuesta tenía entre 18 y 29 años de edad.

Los cuadros 5 y 6 presentan por separado las distribuciones porcentuales de las poblaciones masculinas y femeninas de 18 a 29 años de edad según su estado civil para los cinco municipios de Baja California en el año 2006. Respecto de las jóvenes, en el cuadro 5 vemos que en ese entonces poco más de la mitad de ellas eran solteras, al momento de la entrevista, representando aproximadamente 53\% del total de la población femenina de estas edades en el estado. Mexicali era el municipio con el mayor porcentaje de solteras (61.6\%), seguida de Ensenada y Tecate con 56.9\% y $57.4 \%$ de casos respectivamente; mientras que Tijuana tenía la menor proporción de solteras con $47.4 \%$ de casos, seguida muy de cerca por Rosarito con $48.5 \%$. En contraparte, las jóvenes de 18 a 29 años de edad ya casadas o unidas en el estado representan $41.4 \%$ del total de la población femenina de estas edades, teniendo a Tijuana a la cabeza con el porcentaje más alto de mujeres jóvenes casadas o unidas (47.2\%), seguida por Rosarito con un promedio de 43.3\%; en tanto que Mexicali y Ensenada tenían los porcentajes más bajos de mujeres jóvenes casadas o unidas.

$\mathrm{Al}$ hacer la comparación entre los sexos es interesante ver en el cuadro 6 que, como era de esperarse y siguiendo el patrón tradicional de la nupcialidad mexicana, hay más solteros que solteras de estas edades, siendo que a nivel estatal, aproximadamente $63 \%$ de ellos y $53 \%$ de ellas son solteros. El mayor número de solteros que solteras se repite en cada uno de los municipios. Tecate y Ensenada llegan a tener porcentajes hasta 10 puntos superiores que Mexicali en la proporción de varones jóvenes solteros, especialmente en el caso de Tecate con casi $75 \%$ de la población masculina de 18 y 29 años de edad en esta categoría de estado civil; en tanto que, al igual de lo que ocurre con la población femenina de las mismas edades, Tijuana y Rosarito tienen los porcentajes más bajos de varones jóvenes solteros: $59.5 \%$ y $58.3 \%$, respectivamente.

En correspondencia, la proporción de varones casados o unidos es menor que la de mujeres casadas o unidas. Sólo un poco más de una tercera parte del total de la población masculina de 18 a 29 años de edad en Baja California estaba casada o unida al momento de la encuesta (34.3\%), en comparación al $41.4 \%$ de ellas. Tecate es el municipio con la menor proporción de hombres de 18 a 29 años de edad casados o unidos y Tijuana 
Cuadro 5. Estado civil de la población femenina de 18 a 29 años de edad en Baja California, 2006 (\%)

\begin{tabular}{|l|c|c|c|c|c|c|}
\hline \multirow{2}{*}{\multicolumn{1}{c|}{ Estado conyugal }} & \multicolumn{5}{c|}{ Municipio } & \multirow{2}{*}{ Total } \\
\cline { 2 - 7 } & Ensenada & Mexicali & Tecate & Tijuana & Rosarito & \\
\hline Vive en unión libre & 17.2 & 13.2 & 20.4 & 24.4 & 21.7 & 20.3 \\
\hline Es casada & 18.4 & 19.1 & 19.6 & 22.8 & 21.6 & 21.1 \\
\hline Es viuda & 0.3 & 0.2 & & 0.2 & & 0.2 \\
\hline Es divorciada & 1.5 & 1.4 & & 0.4 & & 0.8 \\
\hline Es separada de matrimonio & 2.3 & 1 & 1.6 & 1.2 & & 1.3 \\
\hline Es separada de unión libre & 3 & 3.5 & 1.5 & 3.6 & 8.2 & 3.6 \\
\hline Soltera & 57.3 & 61.6 & 56.9 & 47.4 & 48.5 & 52.7 \\
\hline Total & 100 & 100 & 100 & 100 & 100 & 100 \\
\hline
\end{tabular}

Fuente: Estimaciones propias. Encuesta de Salud Reproductiva en la Adolescencia, Baja California, 2006.

\section{Cuadro 6. Estado civil de la población masculina de 18 a 29 años de edad en Baja California, 2006 (\%)}

\begin{tabular}{|l|c|c|c|c|c|c|}
\hline \multirow{2}{*}{\multicolumn{1}{|c|}{ Estado conyugal }} & \multicolumn{5}{c|}{ Municipio } & \multirow{2}{*}{ Total } \\
\cline { 2 - 7 } & Ensenada & Mexicali & Tecate & Tijuana & Rosarito & \\
\hline Vive en unión libre & 14.3 & 17 & 10.6 & 20.4 & 33.9 & 18.7 \\
\hline Es casado & 12.3 & 16.1 & 14.9 & 17 & & 15.6 \\
\hline Es divorciado & 0.4 & & & 0.2 & & 0.2 \\
\hline Es separado de matrimonio & 0.7 & 1.5 & & 1.5 & & 1.3 \\
\hline Es separado de unión libre & 1.9 & 1 & & 1.4 & 7.8 & 1.5 \\
\hline Soltero & 70.4 & 64.4 & 74.5 & 59.5 & 58.3 & 62.7 \\
\hline Total & 100.0 & 100 & 100 & 100 & 100 & 100 \\
\hline
\end{tabular}

Fuente: Estimaciones propias. Encuesta de Salud Reproductiva en la Adolescencia, Baja California, 2006. 
es el municipio con el porcentaje más alto de jóvenes en esta situación de conyugalidad.

La práctica tradicional mexicana de que las mujeres se casen a edades menores que los hombres nos permite darle sentido al hecho de que haya más solteros que solteras entre los 18 y 29 años de edad, pero esta práctica no nos permite dar sentido a las diferencias que se observan entre los sexos respecto del número relativo de jóvenes casados versus jóvenes en uniones libres o consensuales. Sobre este particular, la comparación de los cuadros 5 y 6 permite identificar algunos aspectos interesantes. Entre las jóvenes, son ligeramente más las casadas que las unidas a nivel estatal, mientras que entre los hombres son más los que declararon vivir en unión libre que en matrimonio, con tres puntos porcentuales de diferencia. Nótese que tres de los cinco municipios tienen porcentajes más altos de mujeres jóvenes que viven en unión libre que casadas. En este sentido, Tijuana presenta los porcentajes más altos de mujeres jóvenes viviendo en unión libre (24.4\%), seguida muy de cerca por Rosarito y Tecate con $21.7 \%$ y $20.4 \%$, respectivamente, de jóvenes mujeres en la misma situación. Por su parte, Ensenada y Mexicali tienen más mujeres jóvenes casadas que unidas de manera consensual aunque no con mucho, especialmente en el caso de Ensenada, donde las diferencias son menores al uno por ciento a favor de las casadas.

En el caso de la población joven masculina es interesante observar que, según los datos del cuadro 6, con excepción de Tecate todos los municipios presentan porcentajes mayores de jóvenes viviendo en unión libre que casados. El caso extremo lo presenta Rosarito donde todos declararon vivir en unión libre y ninguno casado; situación que llama la atención dado que las proporciones de mujeres jóvenes casadas y unidas en este mismo municipio son prácticamente iguales.

Sobre la población de jóvenes con uniones conyugales disueltas se tiene la circunstancia de que ninguno de ellos se declaró como viudo y sólo un número pequeñísimo de ellas lo hicieron como viudas $(0.2 \%)$, lo cual es entendible por tratarse de poblaciones muy jóvenes. Por su parte, la población con uniones disueltas por divorcio y separación de un matrimonio es de $2.1 \%$ entre ellas y de sólo $1.5 \%$ entre ellos a nivel estatal; en tanto que las separaciones de una unión libre son un poco mayores entre ellas (3.6\%) y prácticamente iguales entre ellos (1.5\%). Las diferencias entre 
los sexos observables en estas categorías de estado civil pudieran explicarse en gran parte por el hecho, bien documentado en otros estudios, de las mayores probabilidades que, en lo general, tienen los hombres, principalmente jóvenes, de casarse o unirse nuevamente después de experimentar la disolución de su primera unión o matrimonio. Si bien existen algunas diferencias al respecto entre los distintos municipios, llama la atención que por su parte Rosarito tenga los porcentajes de separaciones de uniones libres más altos entre las dos poblaciones de jóvenes: $8.2 \%$ entre ellas y $7.8 \%$ entre ellos.

La importancia de las uniones consensuales entre los jóvenes de Baja California es contundente dado que los arreglos conyugales se dividen casi por igual entre uniones de este tipo y matrimonios. Este tipo de arreglo conyugal incluso rebasa la mitad de la población de 18 a 29 años de edad que declaró estar unida conyugalmente en los casos de Tijuana y Rosarito.

\section{Tipos de arreglos conyugales y nacimiento de hijos}

En relación con la naturaleza social de las uniones libres, es importante diferenciar por lo menos entre dos modalidades que son, por un lado, la unión libre como etapa inicial en la formación familiar, siguiendo la practica tradicional mexicana, y por otro, la unión libre como estilo de vida en las relaciones de pareja entre los jóvenes sin que necesariamente exista el interés o la intención de procrear hijos y formar una familia. Con el propósito de aproximarnos de alguna manera a este aspecto, aunque sea de manera superficial, se presenta en el cuadro 7 información sobre la proporción de la población joven bajacaliforniana que al momento de la encuesta declaró tener al menos un hijo nacido vivo y el número promedio de hijos, según su estado civil y el tipo de arreglo conyugal entre los alguna vez unidos.

En el cuadro 7 podemos ver que $44.4 \%$ de las jóvenes y $33.4 \%$ de los jóvenes de 18 a 29 años de edad declararon tener al menos un hijo nacido vivo y en promedio tienen $1.7 \%$ y $1.6 \%$ hijos, respectivamente. Como era de esperarse, la proporción de solteras y solteros con hijos es notablemente inferior a la de los varios subgrupos de la población alguna vez unidos en ambos sexos: $9.7 \%$ de ellas y $6.3 \%$ de ellos. En cambio, la 
Cuadro 7. Proporción de jóvenes de 18 a 29 años en Baja California según sexo y estado civil con al menos un hijo y promedio de hijos, $2006(\%)$

\begin{tabular}{|l|c|c|c|c|}
\hline \multirow{2}{*}{\multicolumn{2}{|c|}{ Estado civil }} & \multicolumn{2}{c|}{ Mujeres } & \multicolumn{2}{c|}{ Hombres } \\
\cline { 2 - 5 } & $\begin{array}{c}\text { Con al menos un } \\
\text { hijo (\%) }\end{array}$ & Hijos & $\begin{array}{c}\text { Con al menos } \\
\text { un hijo (\%) }\end{array}$ & Hijos \\
\hline Total & 44.4 & 1.7 & 33.4 & 1.6 \\
\hline Unión libre & 80.2 & 1.8 & 74.2 & 1.6 \\
\hline Casado/a & 87.8 & 1.8 & 85.7 & 1.6 \\
\hline Divorciado/a & 55.1 & 2.1 & 31.4 & 1 \\
\hline Separado/a de matrimonio & 77.8 & 1.8 & 77.1 & 1.5 \\
\hline Separado/a de unión libre & 81.9 & 1.6 & 72.3 & 1.3 \\
\hline Soltero/a & 9.7 & 1.6 & 6.3 & 1.2 \\
\hline Viudo/a & 77.1 & 1.7 & & \\
\hline
\end{tabular}

Fuente: Encuesta de Salud Reproductiva en la Adolescencia, Baja California, 2006.

proporción de la población joven alguna vez unida que tiene al menos un hijo oscila entre $55.1 \%$ y $87.8 \%$ en ellas y entre $31.4 \%$ y $77.1 \%$ en ellos. Ahora bien, al comparar sólo a la población casada y en unión libre vemos que la proporción de con al menos un hijo es superior entre las casadas y los casados que entre las y los unidos consensualmente, y que si bien las diferencias entre los dos tipos de arreglos conyugales son marcadas, en ambos casos se trata de cifras muy elevadas. De tal modo que $80.2 \%$ de ellas y $74.2 \%$ de ellos viviendo en unión libre tienen al menos un hijo y el número promedio de hijos es de $1.8 \%$ y $1.6 \%$, respectivamente. Aún más, nótese que el promedio de hijos entre los dos tipos de arreglos conyugales es igual tanto entre ellas como entre ellos. Estas cifras sugieren que la gran mayoría de las y los jóvenes de Baja California que viven en unión libre están construyendo sus familias de procreación al igual que lo están haciendo las y los jóvenes casados. Únicamente una quinta parte de las jóvenes y una tercera parte de los jóvenes que al momento de la encuesta vivían en unión libre, mantenían relaciones de pareja libres de compromisos adquiridos con el nacimiento de hijos en común o con alguna pareja anterior. 
Finalmente, importa considerar el nivel educativo de la población joven de Baja California. Esto es con el fin de tener una idea acerca del capital humano con que cuentan los y las jóvenes para enfrentar las responsabilidades sociales que implica establecer una relación conyugal de cualquiera de los dos tipos, pero principalmente formar una familia mediante el nacimiento de hijos. Al respecto, observamos en el cuadro 8 que a nivel del estado en su conjunto, prácticamente no existen diferencias entre la escolaridad máxima alcanzada entre las y los jóvenes de 18 a 29 años de edad. Las diferencias entre los sexos se manifiestan cuando consideramos su estado civil. Entre la población soltera encontramos que ellas tienen un nivel de escolaridad un poco más alto que ellos; de tal manera que mientras $60 \%$ de los jóvenes varones tiene al menos estudios de preparatoria, 69\% de ellas tiene ese mismo nivel escolar. Sin embargo, esta superioridad femenina en la escolaridad no se presenta en los varios subgrupos de la población alguna vez unida, con excepción del grupo de separados de una unión libre donde ellas superan con mucho a ellos. En todos los otros grupos, los varones tienen mayores niveles de escolaridad que las mujeres, especialmente entre los grupos de divorciados y separados de un matrimonio.

Al comparar sólo a los grupos de casados y que vive en unión libre, notamos dos aspectos importantes. Un primer aspecto es que la superioridad escolar masculina es más marcada entre los y las unidas que entre los y las casadas. En el primer grupo la diferencia entre ellos y ellas es de 8.7 puntos porcentuales a favor de ellos; en tanto que en el segundo grupo la diferencia es de sólo 3.4 puntos porcentuales también a favor de ellos. El segundo aspecto se refiere a que, en ambos sexos, la población casada tiene niveles educativos superiores a la población unida y las diferencias entre los dos grupos no son nada despreciables, especialmente en el caso de ellas. Mientras que 9\% más de varones casados que de varones unidos tiene por lo menos estudios de preparatoria, $14.3 \%$ más de las casadas que las unidas tiene este mismo nivel de escolaridad.

Estos datos nos permiten inferir que, por un lado, los y las jóvenes en unión libre presentan condiciones más desventajosas que los y las jóvenes casadas para enfrentar las responsabilidades de establecer una relación conyugal y de formar una familia. Esto es a juzgar por las implicaciones que tienen los menores niveles de escolaridad del primer grupo de jóvenes 
respecto del segundo en su búsqueda de oportunidades de empleo en una economía globalizada, tecnificada y competitiva que requiere de mayores niveles de escolaridad. Y por otro, podría inferirse que tanto las casadas como las que viven en unión libre enfrentan aún condiciones de mayor desventaja que los varones, pero en especial aquellas que viven en unión libre o consensual.

\section{Cuadro 8. Escolaridad en jóvenes de 18 a 29 años de edad en Baja California, por sexo y estado civil (\%)}

\begin{tabular}{|l|c|c|c|c|}
\hline \multicolumn{2}{|c|}{ Estado civil } & \multicolumn{3}{c|}{ Escolaridad (\%) } \\
\cline { 3 - 5 } \multirow{2}{*}{ Total } & Sombre & 12.1 & 36.6 & 51.3 \\
& Mujer & 12.8 & 36.1 & 51.2 \\
\hline \multirow{2}{*}{ Union Libre } & Hombre & 17 & 50.6 & 32.4 \\
& Mujer & 23.8 & 52.5 & 23.7 \\
\hline \multirow{2}{*}{ Casado(a) } & Hombre & 11.9 & 46.8 & 41.4 \\
\hline \multirow{2}{*}{ Divorciado(a) } & Mujer & 15.5 & 46.5 & 38 \\
\hline \multirow{2}{*}{ Separado(a) } & Hombre & & 31.4 & 68.6 \\
de matrimonio & Mujer & 12.6 & 46.9 & 40.5 \\
\hline Separado(a) & Mujer & 13.8 & 21.6 & 55.4 \\
de unión libre & Hombre & 65.4 & 55.9 & 30.3 \\
\hline \multirow{2}{*}{ Soltero(a) } & Mujer & 13.1 & 21.4 & 13.2 \\
\hline Viudo(a) & Hombre & 9.4 & 59.7 & 28.1 \\
\hline
\end{tabular}

Fuente: Estimaciones propias. Encuesta de Salud Reproductiva en la Adolescencia, Baja California, 2006. 


\section{Conclusiones}

Los resultados obtenidos en este estudio confirman que Baja California es el estado con la proporción más alta de uniones libres o consensuales en la región norte del país, así como también que tiene una estructura conyugal donde el orden jerárquico tradicional entre los diferentes tipos de arreglos conyugales se ha visto revertido totalmente. De tal forma que la unión libre ocupa ya el primer lugar en la estructura conyugal del estado de la población de 12 años y más de edad, seguida muy de cerca por el matrimonio sólo civil, mientras que el matrimonio civil y religioso ha pasado a ocupar el tercer lugar, precedido únicamente por el matrimonio sólo religioso que está casi en extinción. Al interior del estado, esta misma estructura conyugal se presenta solamente en el municipio de Tijuana, reflejando el peso que tiene la población tijuanense en la dinámica conyugal del conjunto estatal. Pero también es evidente que la unión libre está siendo cada vez más frecuente en la mayoría de los municipios de Baja California, por ser el tipo de unión conyugal más frecuente en Rosarito y Ensenada, así como es el segundo tipo más frecuente en el municipio de Tecate.

La elección de la unión libre como arreglo conyugal se refleja de manera clara entre los y las jóvenes bajacalifornianas a nivel estatal, pero en particular entre aquellos y aquellas que residen en los municipios de Tijuana y Rosarito, seguidos muy de cerca por los que viven en Tecate y, en menor medida, por los de Ensenada y Mexicali, respectivamente. Ahora bien, al parecer la práctica extendida de las uniones libres o consensuales entre los y las jóvenes está asociada al proceso de formación de sus familias de procreación, por ser muy alto el porcentaje de ellos y ellas que declaró tener al menos un hijo nacido vivo. En este sentido, se comportan casi igual que los y las jóvenes casadas, además de que el número promedio de hijos nacidos es prácticamente el mismo en ambos grupos de jóvenes: casados y unidos. Esta situación nos hace pensar en una posible continuidad en la importancia que tradicionalmente han tenido las uniones libres o consensuales en el proceso de formación familiar en México, pero ahora en proporciones mayores entre los jóvenes. La constatación de esto, sin embargo, requiere de futuros estudios más profundos, considerando particularmente la legalización y sacralización de las uniones 
libres en etapas más avanzadas del curso de vida conyugal. Asimismo, conviene realizar estudios acerca de las motivaciones que pudieran tener hombres y mujeres para establecer una unión libre en lugar de casarse, así como acerca de los significados sociales asignados a este tipo de unión conyugal entre las generaciones jóvenes, a diferencia de las motivaciones y significados sociales que le asignaban las generaciones más viejas en el pasado reciente y lejano. Quedan pendientes tales estudios.

\section{Bibliografía}

Consejo Nacional de Población (Conapo). (2011). Perfiles de salud reproductiva. Baja California: unfPA, Conapo, Secretaría de Gobernación.

Coubés, M. L. y González, R. S. (2011). Experiencia de vida de los jóvenes en Tijuana. En N. Ojeda y M. E. Zavala-Cosío, Jóvenes fronterizos/border youth: Expectativas de vida familiar, educación y trabajo hacia la adultez (pp. 57-78). México: El Colegio de la Frontera Norte.

Díaz, M. del C. (2002). El concubinato en México (Tesis). Universidad del Pedregal, México.

González, H. (2011). Caracterización sociodemográfica de la población en tránsito a la vida adulta en Tijuana. En N. Ojeda y M. E. Zavala-Cosío, Jóvenes fronterizos/border youth: Expectativas de vida familiar, educación y trabajo hacia la adultez (pp. 23-56). México: El Colegio de la Frontera Norte.

Gómez, J. (2001). Los cambios en la nupcialidad y la formación de familias: Algunos factores explicativos. En J. Gómez y C. Rabell (Coords.), La población de México: Tendencias y perspectivas sociodemográficas hacia el siglo XXI (pp. 207241). México: Fondeo de Cultura Económica, Conapo.

Ojeda, N. (2013a). Las uniones libres o consensuales en la frontera norte de México. Estudios Demográficos y Urbanos, 28 3(84), 645-679 .

Ojeda, N. (2013b). Cambios y continuidades de la unión libre en México: El caso de las jóvenes en Tijuana. Perfiles Latinoamericanos, 21(42), 193-224.

Ojeda, N. (2010). Diversidad en la formación y en la disolución de las familias en México. En S. Lerner y L. Melgar (Coords.), Familias en el siglo XxI: Realidades diversas y políticas públicas (pp. 137-159). México: Universidad Nacional Autónoma de México, El Colegio de México, Programa Universitario de Estudios de Género.

Ojeda, N. (2009). Matrimonio y unión libre en la percepción de adolescentes mexicanos radicados en Tijuana, estado de México. Papeles de Población, nueva época, 15(60), 41-64. 
Ojeda, N. (2007). La nupcialidad femenina en México al inicio del nuevo milenio. Diferencias rurales y urbanas. En A. M. Chávez, P. Uribe y Y. Palma (Coords.), La salud reproductiva en México: Análisis de la Encuesta Nacional de Salud Reproductiva 2003 (pp. 123-132). México: Secretaría de Salud, Universidad Nacional Autónoma de México, Centro Regional de Investigaciones Multidisciplinarias.

Quilodrán, S. J. (2001). Un siglo de matrimonio en México. México: El Colegio de México.

Palma, Y. y Reding, B. A. (2011). Características del inicio de la vida sexual y reproductiva de las jóvenes de Tijuana. En N. Ojeda y M. E. Zavala-Cosío (Coords.), Jóvenes fronterizos/border youth: Expectativas de vida familiar, educación y trabajo hacia la adultez (pp. 79-102). México: El Colegio de la Frontera Norte, Consejo Nacional de Ciencia y Tecnología.

Pérez, J. y Esteve, A. (2012). Explosión y expansión de las uniones libres en México. Coyuntura Demográfica. Revista sobre los Procesos Demográficos en México Hoy, (2), 41-44.

Rodríguez, J. A. (2004). Cohabitación en América Latina: ¿Modernidad, exclusión o diversidad? Papeles de Población, (40), 97-145. 